\title{
Suction assisted lipectomy [SAL] as a replacement for conventional surgical excision of subcutaneous lipomata
}

\author{
Rao $S^{1}$, Bhat U.B ${ }^{2}$, Patel B.K ${ }^{3}$ \\ ${ }^{1}$ Prof. Shilpa Rao, Professor and Unit Head, Department of General Surgery, Seth G.S. Medical College and K.E.M. \\ Hospital, Mumbai, India, ${ }^{2}$ Dr Uday B Bhat, Additional Professor, Department of Plastic Surgery, Topiwala National \\ Medical College and Nair Hospital, Mumbai, ${ }^{3}$ Dr Bharat K. Patel, Honorary Plastic Surgeon, Kasturba Hospital, \\ Mumbai, Maharashtra, India
}

Address for Correspondence: Prof. Shilpa A. Rao, Department of Surgery, Seth G. S. Medical College \& KEM Hospital, Acharya Donde Marg, Parel, Mumbai, Maharashtra. E-mail address: ateeshilpa@gmail.com

\begin{abstract}
Introduction: Lipomata are avascular, painless, slow growing benign tumors of mature fat cells. Surgery is often sought for aesthetic reasons. Conventional excision of lipomata leads to visible scarring which in cases of large or multiple lipomata can be contrary to the purpose of the consult. We present the preliminary results of a novel suction assisted technique for lipoma excision developed at our institute. Materials and Methods: 18 patients with subcutaneous lipomata were included, who among them had a total of 51 lipomata. A suction cannula was inserted through a single sub- centimetric aesthetically placed incision under local anaesthesia to excise the lipomata. Postoperative complications and cosmetic outcomes were noted. Results: Complete excision of up to 17 lipomata was possible in all patients through a single sub- centimetric incision. Cosmetic results were excellent without any intra- or post- operative complications. Conclusion: Suction assisted lipectomy (SAL) is an aesthetic, simple and safe technique requiring no special training, with complete lipomata clearance with minimal complications. We strongly recommend that SAL with capsular extraction as an ideal replacement for conventional surgery in moderate $[4-10 \mathrm{~cm}]$ to large lipomata $[>10 \mathrm{cms}]$ and in multiple lipomatosis.
\end{abstract}

Key words: Suction assisted lipectomy; Liposuction; Lipoma; Tumescent anaesthesia

\section{Introduction}

Lipomata, which commonly present as painless subcutaneous swellings are the most common benign soft tissue tumours, and are composed of mature fat cells $[1,2]$. Surgery is often sought for aesthetic reasons. Larger lipomata require large surgical incisions for excision which can produce undesirable cosmetic outcomes. Also, multiple lipomata necessitate multiple incisions, which again lead to an unfavorable cosmesis. Since the first application of liposuction for giant lipomata by Rubenstein et al. [3] several authors have studied the utility of this technique for excision of lipomatas to avoid the cosmetic deformities caused by large or multiple surgical incisions $[4,5,6]$. Endoscopic removal of lipomata was described by Hallock [7] providing complete capsule removal, which is the

Manuscript received 24 $4^{\text {th }}$ April 2016

Reviewed: $7^{\text {th }}$ May 2016

Author Corrected: $22^{\text {nd }}$ May 2016

Accepted for Publication $5^{\text {th }}$ June 2016 essential step in preventing recurrence. In our study we describe a low- cost modification to the technique of suction assisted lipectomy (SAL) for removal of subcutaneous lipomata.

\section{Materials and Methods}

Study sample: This was a non- randomized prospective trial conducted at our institute, a tertiary level government health care centre. A purposive sampling method was used. 18 patients with single or multiple subcutaneous lipomata were included in the study.

\section{Inclusion criteria}

1. Patients with single $(>3 \mathrm{~cm})$ or multiple subcutaneous lipomata.

2. Age between 25 to 60 years. 
3. Diagnosis of lipoma confirmed by fine needle aspiration cytology (FNAC).

\section{Exclusion criteria}

1. Known bleeding disorders or coagulation defects.

2. Deranged platelet counts

3. Deranged prothrombin time (PT).

4. Ongoing antiplatelet or anticoagulant medication.

5. Chronic liver disease.

6. History of trauma preceeding the presentation of the lipoma.

7. Hypersensitivity to local anaesthetic.

8. Lack of consent.

Study design: All patients included in the study underwent the SAL procedure with tumescent anaesthesia and outcomes of the procedure were recorded. Patients were followed- up for 4 years to assess for long term recurrence.

\section{Study end- points}

1. Cosmesis

2. Intra- operative complications

3. Post- operative complications

4. Recurrence

\section{Suction Assisted Lipectomy (SAL): Equipment required}

1. Blunt tipped canula: A metallic suction cannula 3 $5 \mathrm{~mm}$ in diameter with 1-3 peri- apical apertures to allow controlled and safe extraction of fat and avoiding subsequent irregularity in contour.

2. Connecting tubing: Silicone tubings of $12-15 \mathrm{~mm}$ internal diameter and a length of 6-7 feet. The tubing needs to be sufficiently rigid to maintain patency after application of suction and also have a large enough diameter to prevent clogging of aspirated fat.
3. Vacuum pump: Capable of producing a pressure of $760 \mathrm{mmHg}$.

4. Glass bottle: Capacity of $1.5-2 \mathrm{~L}$ for collection of suctioned fat.

Suction Assisted Lipectomy (SAL): Procedure[Fig 1] Local anaesthetic was injected at the incision site, followed by tumescent anaesthesia $(0.1 \%$ lidocaine solution with epinephrine in a concentration of $1: 1,000,000$, and sodium bicarbonate in a concentration of $1 \mathrm{mEq}$ per $10 \mathrm{~mL}$ of lidocaine.

Maximum total dose of lidocaine was $1 \mathrm{mg} / \mathrm{kg}$ ) [8, 9, 10] around the lipoma as well as along the subcutaneous tunnel to be created by the metal cannula. An aesthetically placed incision of length $1 \mathrm{~cm}$ was then taken. A subcutaneous tunnel was created with blunt dissection using artery forceps. The metal suction cannula was then inserted up to the lipoma through the incision. The key step in preventing recurrence is breaking of the capsule of the lipoma as well as the connective tissue strands inside the lipoma with the blunt tip of cannula. Following this, the lipoma along with the capsule was sucked out using a suction pump generating a pressure of $760 \mathrm{mmHg}$. The high suction causes the fat cells to emulsify and get sucked out through the tip of the cannula [11].

Complete excision of the lipoma and the capsule is ensured by lack of resistance to the movement of the tip of the cannula circumferentially. In case of a retained capsule, an artery forceps can be used to complete the excision. Post excision, contouring done as needed to better the results.

Post- operatively, compression dressings were applied for $48 \mathrm{hrs}$ in patients with moderately sized lipomata (4$10 \mathrm{~cm})$, whereas a suction drain was placed in patients with lipomata larger than $10 \mathrm{~cm}$.

\section{Results}

Sample- 18 patients were included in the study. The patients ranged from 25 to 60 years to age with 8 females and 10 males. Six of them had multiple lipomata all over the body especially in the upper limbs. A total of 51 lipomata were removed by suction assisted lipectomy [SAL] along with capsule extraction in the above patients.

The size of the lipomata varied from $4-15 \mathrm{~cm}$. The number of lipomata in patients varied from 5- 17 in patients with multiple lipomata.

Cosmesis [Fig. 2, 3, 4]

Excision of all 51 lipomata was achieved through a single aesthetic sub- centimeter incision in all patients. There was no evidence of post- operative contour abnormalities in any patient. 


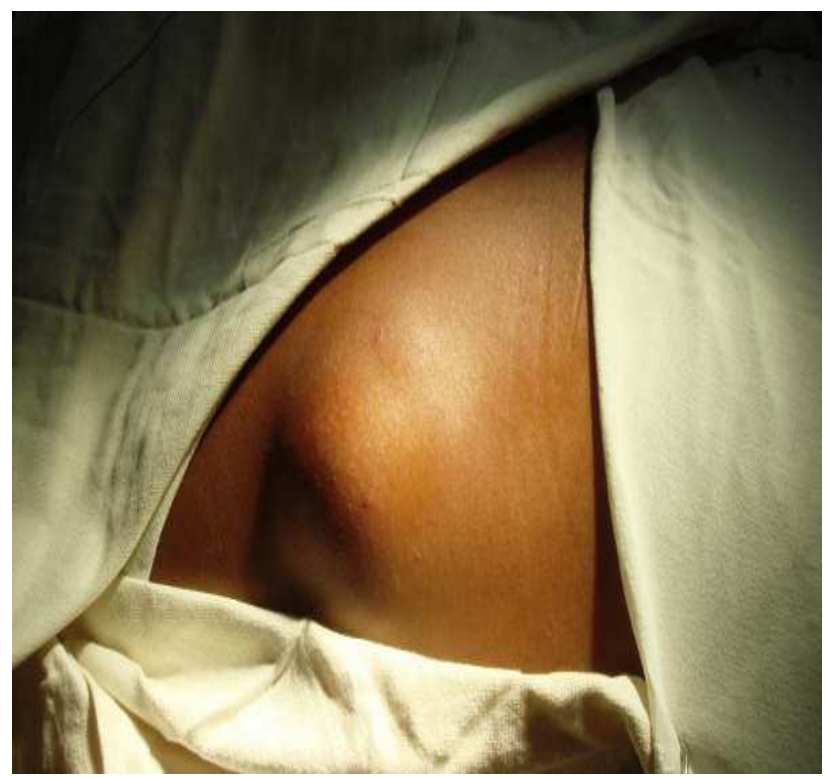

Fig.-1 Metallic suction cannula inserted up to the lipoma through an aesthetically placed sub- centimeter incision.

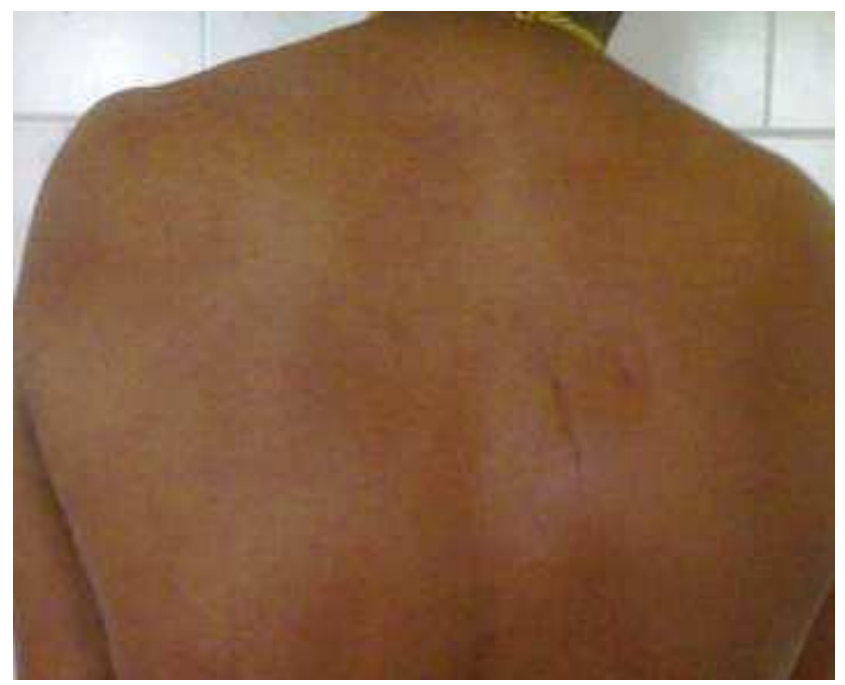

Fig 3: Closure of sub- centimer incision after completion of SAL

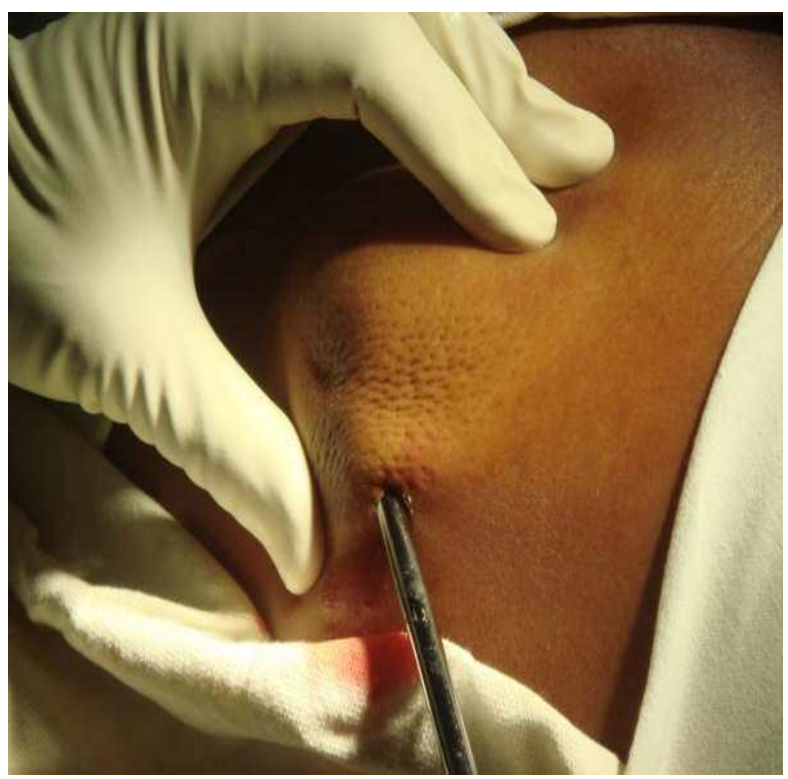

Fig. 2 Lipoma; Pre- operative photograph

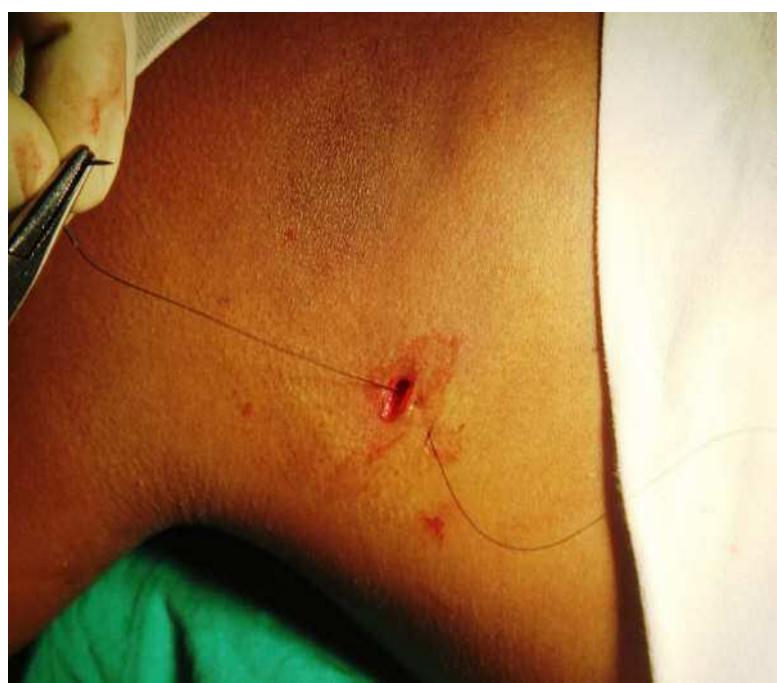

Fig. 4: Post- operative photograph of scar.

Intra- operative complications- There were no intra- operative complications.

Post- operative complications- There were no post- operative complications.

Recurrence- The patients were followed up for a period of 4 years during which none of the patients had any local recurrences.

\section{Discussion}

Lipomata are usually avascular, painless, slow growing benign tumours of mature fat cells with little propensity for malignant change. It is the commonest soft tissue tumor affecting $1 \%$ of population usually $40-60 \mathrm{yrs}$ of age. Most occur on the trunk, thighs and the forearms, although they may be found anywhere in the body where fat is located [1, 2]. Dercums Adiposis dolorosa is a rare condition seen in obese, post menopausal females presenting as multiple painful lipomata [12]. Benign symmetrical lipomatosis or Madelung's disease on the other hand affects middle aged males [13]. Conventional surgical excision of large and multiple lipomata result in significant cosmetic deformity often defeating the purpose of their excision. It may also lead 
to post operative irregularities in the contour. Liposuction became extremely popular for focal fat reduction for cosmetic purposes and is today one of the commonest plastic surgical procedures in the world [14, 15]. It was first applied to the treatment of lipomata around the early 1990's [3].

However, it has not earned a place as a gold standard in their treatment, mainly due to the expensive equipment required. However, in our technique, we achieved complete excision of the lipomata though a single, subcentimeter incision in all patients including post excision contouring, without using specialized equipment, thus making this procedure cost- effective as well.

This procedure is especially advantageous in moderate $(4-10 \mathrm{~cm})$ to large $(>10 \mathrm{~cm})$ lipomata and in patients with multiple lipomata, since the cosmetic outcomes produced in these patients by SAL were much better than if they had undergone conventional surgical excision.

Our findings have been corroborated by various studies which show SAL to have better cosmesis, lesser complications, and similar clearance rates $[4,16]$.

\section{Conclusions}

We strongly recommend that SAL or liposuction along with capsular extraction is an ideal replacement for conventional surgery, especially in moderate $[4-10 \mathrm{~cm}]$ to large lipomata [>10 cms] and in multiple lipomatosis.

Ethical approval and consent- All procedures performed in this study were in accordance with the ethical standards of the institutional research ethics committee and with the 1964 Helsinki declaration and its later amendments or comparable ethical standards.

Informed consent was obtained from all individual participants included in the study.

Disclosure- The authors report no conflict of interest.

Funding: Nil, Conflict of interest: None initiated. Permission from IRB: Yes

\section{References}

1. Goldblum, John R., Sharon W. Weiss, and Andrew L. Folpe. Enzinger and Weiss's soft tissue tumors. Elsevier Health Sciences, 2013.
2. Rhydholm, A., and N. O. Berg. "Size, site and clinical incidence of lipoma."Acta orthop scand 54 (1983): 929-934.

3. Rubenstein R, Roenigk HH Jr, Garden JM, Goldberg NS, Pinski JB. Liposuction for lipomas. J Dermatol Surg Oncol. 1985 Nov;11(11):1070-4.

4. Al-basti, Habib A., and Hamdy A. El-Khatib. "The use of suction-assisted surgical extraction of moderate and large lipomas: long-term follow-up."Aesthetic plastic surgery 26.2 (2002): 114-117.

5. Apesos, James, and Robert Chami. "Functional applications of suction-assisted lipectomy: a new treatment for old disorders." Aesthetic plastic surgery 15.1 (1991): 73-79.

6. Mouly, R., and J. L. Sechaud. "[Treatment of subcutaneous lipomas with liposuction]." Annales de chirurgie plastique et esthetique. Vol. 33. No. 2. 1987.

7. Hallock, Geoffrey G. "Endoscope-assisted suction extraction of lipomas."Annals of plastic surgery 34.1 (1995): 32-34.

8. Ostad, Ariel, Nobu Kageyama, and Ronald L. Moy. "Tumescent anesthesia with a lidocaine dose of 55 $\mathrm{mg} / \mathrm{kg}$ is safe for liposuction." Dermatologic surgery 22.11 (1996): 921-927.

9. Klein, Jeffrey A. "The tumescent technique for liposuction surgery." Am J Cosmet Surg 4.4 (1987): 263-7.

10. SMITH, SHARON L., et al. "The importance of bicarbonate in large volume anesthetic preparations." The Journal of dermatologic surgery and oncology18.11 (1992): 973-975.

11. Shiffman, Melvin A., and Sid Mirrafati. "Fat transfer techniques: the effect of harvest and transfer methods on adipocyte viability and review of the literature." Dermatologic surgery 27.9 (2001): 819-826.

12. Petersen, Palle, and Jens Kastrup. "Dercum's disease (adiposis dolorosa). Treatment of the severe pain with intravenous lidocaine." Pain 28.1 (1987): 77-80.

13. Smith, Paul D., et al. "Benign symmetric lipomatosis (Madelung's disease)."Annals of plastic surgery 41.6 (1998): 671-673. 
14. Gasperoni, Carlo, and Marzia Salgarello. "MALL liposuction: the natural evolution of subdermal superficial liposuction." Aesthetic plastic surgery 18.3 (1994): 253-257.
15.Troilius, Carl. "Ten year evolution of liposuction. "Aesthetic plastic surgery20.3(1996):201-206.

16. Pinski, K. S., and H. H. Roenigk Jr. "Liposuction of lipomas." Dermatologic clinics 8.3 (1990): 483-492.

\section{How to cite this article?}

Rao S, Bhat U. B, Patel B. K. Suction assisted lipectomy [SAL] as a replacement for conventional surgical excision of subcutaneous lipomata. Int J Med Res Rev 2016;4 (6):930-934doi: 10.17511/ijmrr.2016.i06.11. 